\title{
Correction: Extracting Family History Information From Electronic Health Records: Natural Language Processing Analysis
}

\author{
Maciej Rybinski ${ }^{1}$, PhD; Xiang Dai ${ }^{1,2}$, MSc; Sonit Singh ${ }^{1,3}$, MSc; Sarvnaz Karimi ${ }^{1}, \mathrm{PhD}$; Anthony Nguyen ${ }^{4}, \mathrm{PhD}$ \\ ${ }^{1}$ Commonwealth Scientific and Industrial Research Organisation, Sydney, Australia \\ ${ }^{2}$ University of Sydney, Sydney, Australia \\ ${ }^{3}$ Macquarie University, Sydney, Australia \\ ${ }^{4}$ Commonwealth Scientific and Industrial Research Organisation, Brisbane, Australia
}

Corresponding Author:

Maciej Rybinski, PhD

Commonwealth Scientific and Industrial Research Organisation

Marsfield

Sydney

Australia

Phone: 61293724222

Email: $\underline{\text { maciek.rybinski@csiro.au }}$

\section{Related Article:}

Correction of: https://medinform.jmir.org/2021/4/e24020

(JMIR Med Inform 2021;9(5):e30153) doi: 10.2196/30153

In "Extracting Family History Information From Electronic Health Records: Natural Language Processing Analysis" (JMIR Med Inform 2021;9(4):e24020) one correction was made.

Due to a system error, five extraneous figures were added to the Methods section of the paper at the time of publication. These have been removed from the corrected version.
The correction will appear in the online version of the paper on the JMIR Publications website on May 3, 2021, together with the publication of this correction notice. Because this was made after submission to PubMed, PubMed Central, and other full-text repositories, the corrected article has also been resubmitted to those repositories.

This is a non-peer-reviewed article. Submitted 03.05.21; accepted 03.05.21; published 03.05.21.

Please cite as:

Rybinski M, Dai X, Singh S, Karimi S, Nguyen A

Correction: Extracting Family History Information From Electronic Health Records: Natural Language Processing Analysis

JMIR Med Inform 2021;9(5):e30153

URL: https://medinform.jmir.org/2021/5/e30153

doi: $10.2196 / 30153$

PMID:

CMaciej Rybinski, Xiang Dai, Sonit Singh, Sarvnaz Karimi, Anthony Nguyen. Originally published in JMIR Medical Informatics (https://medinform.jmir.org), 03.05.2021. This is an open-access article distributed under the terms of the Creative Commons Attribution License (https://creativecommons.org/licenses/by/4.0/), which permits unrestricted use, distribution, and reproduction in any medium, provided the original work, first published in JMIR Medical Informatics, is properly cited. The complete bibliographic information, a link to the original publication on https://medinform.jmir.org/, as well as this copyright and license information must be included. 